\title{
Siirt Kenti Yöresel Yemek Kültüründe Büryan: Bahattin Büryan Sarayı Örneği
}

\author{
Büryan in Local Food Culture of the City of Siirt: \\ Case of Bahattin Büryan Sarayı
}

\section{Figen Kanbir*}

\begin{abstract}
Öz
İnsan için tüm zamanların en önemli kültür alışkanlığı beslenmedir. Beslenme, yerleşik hayata geçişle birlikte özel alanın sınırları içerisine dâhil edilmiştir. Zamanla, tüm dünyada dışarıda yeme alışkanlığının kazanılması ile farklı kesimlerin beğeni tercihleri birbirinden ayrılmıştır. Yemek kültürü, farklı kesimlere hitap eden restoranlarla büyük şehirlerde varlık göstermiştir. Buralarda yöresel yiyecekleri tercih, başlı başına bir statü mevzusudur. Kırsal özellikler taşıyan küçük ölçekli kentlerde ise, herkesin içeride sahipleneceği yerel restoranların varlığı hissedilmektedir. Bu bağlamda Siirt kenti restoran kültürüyle dikkat çeken örneklerden birini oluşturmaktadır. Çalışmanın amacı, bu restoranlardan biri olan Bahattin Büryan Sarayı'nda servisi yapılan büryanın yöresel yiyecek sayılmasının nedenlerini analiz etmektir. Çalışma nitel araştırma tekniklerinden olan (yarı yapılandırılmış) görüşmeyi, Siirt kenti restoranlarından biri olan Bahattin Büryan Sarayı çalışanlarını örneklem kabul ederek incelemeye almıştır.
\end{abstract}

Geliş tarihi (Received): 26.11.2020 - Kabul tarihi (Accepted): 25.06.2021

* Dr. Öğ. Üyesi. Siirt Üniversitesi Fen Edebiyat Fakültesi Sosyoloji Bölümü. (Siirt University, Faculty of Arts and Sciences, Department of Sociology). f.kanbir_18@hotmail.com. ORCID 0000-0003-2094-399X 
Çalışmada, büryanın yöresel kültürün özelliklerini taşıdığı ortaya çıkmıştır. Özellikle büryan ve Bahattin Büryan Sarayı, hem kamusal hem de özel alanın izlerini taşıyarak, kamusal ile özel alan arasında sahiplenilmiş görünmektedir. Restoranın müşterileri farklı yaş, cinsiyet, yerleşim yeri, eğitim durumu ve sınıfa sahip kimselerden oluşmaktadır. Bununla birlikte restoran, farklı illerden ve ülkelerden gelen insanlara yerelin tanıtılmasında önemli bir aracı görev üstlenmiştir.

Anahtar sözcükler: yemek kültürü, yöresel yemek, büryan, Bahattin Büryan Sarayı

\begin{abstract}
Nutrition is the most important cultural pattern of all time for human beings. Along with humans' transition to a sedentary life style, nutrition has been included within the borders of the private space. In time, gastronomic preferences of different classes started to change with the acquisition of a new custom all over the world: dining out. Food culture has evolved in big cities with restaurants appealing to different classes. In these places preference of local food is an issue of status on its own. Dissimilarly, in small cities with rural characteristics, the presence of local restaurants that everyone can embrace is observed. In this context, Siirt is one of those small cities with an restaurant culture. The aim of the study is to analyze the reasons why büryan, (a kebab dish) served in one of these restaurants, Bahattin Büryan Saray1, is considered a local food. The study was carried out with a qualitative research technique, a (semistructured) interview with the employees working for; Bahattin Büryan Saray1, one of the restaurants in the city of Siirt.

In the study, it is observed that the büryan carries the characteristics of the local culture. The Büryan and Bahattin Büryan Saray1, in particular, seem to be embraced by the public and private spheres, bearing the traces of both. The customers of the restaurant constitute people of different age, gender, place of residence, educational background and social class. In addition, the restaurant takes on an exemplary role for introducing the local culture to visitors from different cities and countries.
\end{abstract}

Keywords: food culture, local food, büryan, Bahattin Büryan Sarayl

\title{
Extended summary:
}

Introduction and research questions \& Purpose: Nutrition culture has changed over time in our country as well as in the World. One of these changes, the dining out custom, has started with modernization history of Turkey (Gürsoy, 2019: 149). In this context, restaurants, which are places adopted from the West to Turkey, are notable examples. Restaurants are important places in terms of publicity for the food culture.

Meat-eating culture is one of the indispensable habits of the Eastern and Southeastern 
Anatolia Regions in Turkey. This habit in the city of Siirt, located in the Southeastern Anatolia Region, reflects the effects of livelihood activities and lifestyle. Siirt has placed eating meat and more specifically, büryan at the center of its food culture as a result of its religion, the long-lived nomadic life in the city and wetlands that prevent agriculture. In this article, restaurant culture has been examined through the büryan, one of the local food habits effective in the traditional city.

By taking the local food habits as the main reference, the study seeks answers to the following questions: People from which social classes prefer büryan? What makes büryan attractive for these classes? Does the preparation, service and presentation of büryan, which is a cultural custom, serve the branding of Siirt province? Is it possible to claim that büryan is a distinctive activity in the ownership of local culture? Is eating meat is a habit that is special to Siirt and the region which you live in?

Literature review: In the world and Turkey, various studies have been conducted about food culture (Goode, 2005; Spang, 2007; Beardsworth ve Keil, 2011; Montanari 2018; Belge 2018; Beşirli 2017; Çayc1, 2019). In these studies, what the local food is in our country was examined by taking into account the economic, social and cultural characteristics (Çapar ve Yenipınar, 2016; Gürsoy, 2019; Y1ldız 2020). Tourism has an effect on highlighting the eating habits. In this respect, a study based on the evaluation of geographically marked products in regional tourism, including the büryan, in the city of Siirt was conducted through interviews (Ceylan ve Samırkaş Komşu, 2020). In a thesis examining Siirt and its surroundings in terms of tourism geography, büryan was mentioned in the sections of Siirt cuisine and eating habits (K1lınç, 2019). There are two studies directly related to büryan and they are in the form of papers presented at congresses (Coşkun et al. 2017; Işkın et al. 2017). Among them, Coşkun et al. (2017) conducted a meeting with the managers and masters of the büryan hall. In the study, the sustainability of büryan in terms of gastronomy has been examined. The study of Işkın et al. (2017) drew attention to the introduction of the province of Siirt and was carried out in the form of a literature review. In terms of methodology, our study used the interview technique like the study carried out by Coşkun et al. However unlike Coşkun et al. it offers the reader a multi-dimensional perspective in terms of introducing the local culture. Although the study has taken into account a single restaurant; it constitutes one of the remarkable examples in terms of revealing the importance that neighboring provinces and countries attribute to büryan.

Methodology:In the study, food culture has been discussed in relation to living conditions and livelihood opportunities. It attempts to interpret the effect of the characteristics of the city of Siirt and its region on the ownership of the büryan. It was carried out with a qualitative research technique, taking Bahattin Büryan Sarayı staff as a sample. In the study, descriptive analysis was made by analyzing the interview records; a purposeful sampling was used. In Bahattin Büryan Saray1, 13 people are working and all of them are males. In the study, waitstaff were included in the sample. Likewise, in the article interview recordings, photographs of the place taken by the researcher and observations obtained in the restaurant were used. 
Results and Conclusions: Past habits survive to a large extent with the dominance of local culture in traditional cities. Undoubtedly, this is due to the fact that the places that are effective in increasing the gastronomic differences between the classes are not formed. Food habits of city of Siirt accord this description. In Siirt, people have adapted to the taste of food as a result of cultural life. If we describe the diversity of the people of this city as a mosaic, we can suggest that this mosaic effect also determines the culture-specific habits.

Although there are büryan and restaurants that can be associated with it in Bitlis and Muş, which are close to Siirt, it carries many characteristics of Siirt city in terms of its unique taste and identity. In the study, in the light of the information obtained from Bahattin Büryan Palace employees in Siirt, the following conclusions have been reached:

In Siirt, preparation of the büryan and restaurant working habits are against modern standardization and global food culture with their many features. Many features such as cooking, preparation, presentation and service of büryan have different features than the fastfood habit, which is the global uniform food habit. Restaurant and büryan has different features than modern standards. Among these features, there are reasons such as the training of the staff, working hours, and the difference between the customer and the employee is not clearly drawn.

Nowadays, all stages of nutrition have become professional activities. One of the striking features of the restaurant at this point is that the employees have not received any professional training. With master-apprentice training, employees transfer food preparation and presentation from one culture to another. However, there is no rigid difference in division of labor among restaurant staff. Instead, the need directs people to work in different areas within the restaurant.

In addition, there is no rigid distinction between restaurant staff and customers. This situation was most evident in the participants' addressing their customers as guests throughout the interview. While employees show interest in customers with such a manner, customers also embrace employees in a friendly and amiable way. People have achieved the comfort and reliability of their home insomuch in this restaurant to a great extent. In this respect, it can be said that the clear distinction between private and public sphere, which is another modern standardization, is not observed in this restaurant. Thus, the restaurant has created a culture between private and public sphere.

Büryan Kebab attracts attention with its similarity to the slow food movement developed against the fast food culture in 1986. Büryan begins to be cooked at two o'clock at night. It takes nearly two hours to cook depending on the quality of the meat and fire. Büryan, with its natural cooking method and the absence of tail fat, has been evaluated by employees as light, long-lasting, and beneficial to health. Unlike the modern time limitation, the büryan service in Siirt starts at a very early hour in the morning, with the morning prayer. The büryan service is completed at 5:00 pm. There was no study conducted by the medical community regarding its benefits for health when this research was carried out. Despite this, in the study, restaurant staff verbally expressed the benefits of büryan for health. 
Preferred by people from every walk of life, Bahattin Büryan Sarayı has different features from modern cities where the scales of taste differ. Preferring local foods provides prestige to people in modern cities. However, people from every walk of life (different age, gender, educational status, class, etc.) prefer. In particular, some features such as its affordable price, light food, and long-term fullness ensure such accessibility both inside and outside of the city.

It is stated by the participants that the büryan has made an important contribution to the promotion of the city of Siirt to other provinces and different countries. The fact that Siirt is a small city has prevented the city from being recognized from outside and turned into a center of attraction. Thanks to Büryan, the city was publicized, insomuch that when it comes to büryan, Siirt comes to mind. This situation paves the way for the branding of the city of Siirt. With the effect of all these reasons explained in the study, it has been revealed that büryan in Siirt is an important complement to the local food culture.

\section{Giriş}

İnsanın kendi bedenini tanıması ile kendine yarayan besinleri dengeli öğünler haline getirmesi, nispeten yakın dönemli gelişmelerdendir. Ancak yemek kültürünün gelişimi bütün toplumlar için aynı şekilde gerçekleşmemiştir. Bu kültürel farklılıklar, coğrafi kıstasların birer getirisi olduğu kadar, tarih boyunca oluşturulan geçim faaliyetlerinin alanı içerisinde yer almaktadır. Günümüzde küreselleşmenin etkisiyle insan, kültür, yaşam biçimi, yemek kültürü gibi benzer değerler sahası gün geçtikçe belirginleşmektedir. Bunlar içerisinde nispeten yerel farklılıklar, yeni cazibe merkezleri haline gelmektedir. Bu yerel farklılıkların en çok yaşam alanı bulduğu mekânlar geleneksel kentlerdir. Geleneksel kentlerde doğal olanın hâkimiyeti her alanda kendisini göstermektedir. Bunlardan biri çalışmanın temelinde yer alan yemek kültürüdür. Yemek kültürü, yerel kültürün yaşamasına firsat vermekte; yerel kültür de yemek kültürünü yönlendirmektedir. Toplumdaki farklılıklar ne kadar belirgin olursa olsun, yemek kültürü kişiler arasında ortak bağ yaratabilmektedir.

Lokantalar ve restoranlarla birlikte yemek yeme alışkanlığı, evin içinde hasrolunan bir edim olmaktan kurtularak, kamusal alana bütün yönleriyle sirayet etmiştir. Öyle ki yeme ile kamusal alanın düzenlenişi, üretimden başlayarak tüketime kadar bütün süreçleriyle kültür haline gelmiştir. Bağlı bulunan kültürün tanıtılması, yerel paylaşım ağlarının genişlemesi olarak okunabilecek bu gelişme, yemeğin karın doyurmaktan çok daha fazla işleve sahip olduğunu göstermektedir. Bu bağlamda lokanta ve restoranlar, karın doyurmanın yanı sıra iyi yemek, statü sağlamak, sosyalleşmek gibi konularda kişilere avantaj sağlamaktadır. Bugün yemek konusunda yerel, bölgesel ve küresel düzeyde pek çok çalışma, yemenin kültürü büyük ölçüde belirlediğini, yönlendirdiğini göstermektedir

İncelemeye aldığımız Siirt kentinin temel geçim kaynakları tarım ve küçükbaş hayvanc1lıktır. Siirt’te bunlar büyük oranda yeme kültürünü belirlemektedir. Özellikle göçebe yaşam tarzının etkisiyle hayvancılığın temel geçim faaliyeti olarak uzun zamandır sürdürülmesi, yemek kültürünün kaynağında etin görülmesine sebep olmuştur.

Çalışmada Siirt kenti büryan işletmelerinden birisi olan Bahattin Büryan Sarayı 
incelenmiştir. Siirt’te büryan genellikle kahvaltı saatlerinde tüketilmektedir. Büryan servisi sabah 5:00'te başlayıp, 17:00'de bitmektedir. Bu bağlamda modern çalışma saatlerinin dışında, küresel kültürün karşısında, büryan yerel kültürün devamını sağlamaktadır. Tescilli bir ürün olan büryan, yerel kültürün sürekliliğini sağlamakla birlikte, Siirt kentinin tanıtılmasına katkı sağlamaktadır.

Çalışma nitel araştırma tekniklerinden görüşmeyle gerçekleştirilmiştir. Araştırmanın ilk kısmı alanyazın için ayrılmış olup, ikinci kısımda araştırmanın bulguları ve değerlendirilmesi sunulmuştur.

\section{Araştırmanın amacı, önemi, evren ve örneklemi}

İnsan hayatında yeme ve içme kültürü toplumların doğal ve kültürel koşullarının bir sonucudur. Bu bağlamda yeme ve içmenin üretim, hazırlanma, sunum ve tüketim aşamalarının doğa, mutfak, kültür ekseninde şekillendiği görülecektir. Çalışma büryan kebabını referans alarak, dışarıda yemek kültürünün edinildiği kültürel süreklilikten hareket etmiştir. Bunu Siirt kenti yöresel et restoranlarından biri olan Bahattin Büryan Sarayı'ndan hareketle izlemektedir.

Çalışma nitel araştırma tekniği olan görüşme ile gerçekleştirilmiştir. Nitel araştırmacılar olayların ve bağlamların dilini konuşur; toplumsal yaşamın doğal akışında ortaya çıkan olayları ayrıntılı inceler. Belirli toplumsal-tarihsel bağlamlara duyarlı olan özgün yorumlar sunmaya çalışırlar (Neuman, 2016: 224). Görüşme bir araştırmacıyla bir üyenin ortak ürünüdür. Görüşmede üyeler anlayışları, hisleri ve işbirliklerinin öznel anlamlar açığa çıkaran bir tartışma sürecinin parçası olduğu etkin katılımcılardır (2016: 585). Çalışmada amaca yönelik örneklem tercih edilmiştir. Amaca yönelik örnekleme özellikle bilgilendirici olan benzersiz örnek olayları seçmek için uygundur (2016: 323). Siirt’te büryan hazırlama ve sunumu erkek çalışanlarca gerçekleştirilmektedir. İncelediğimiz restoranda çalışanların tamamı (13 kişi) erkeklerden oluşmaktadır. Biz farklı yaş ve eğitim durumlarını dikkate alarak restoran çalışanlarından 7 kişiyi örneklem kabul ettik. Aşağıdaki tabloda çalışanların bilgileri yer almaktadır:

Tablo 1: Katılımc1 ${ }^{1}$ Bilgileri

\begin{tabular}{|l|l|l|l|}
\hline $\begin{array}{l}\text { Katılımcı } \\
\text { İsmi }\end{array}$ & Yaşı & $\begin{array}{l}\text { Ĕgitim } \\
\text { Durumu }\end{array}$ & Çalıştığı Süre \\
\hline İbrahim & 31 & Lise terk & 13 yıl \\
\hline Mustafa & 44 & Ortaokul & 13 yıl \\
& & & (büryanda ise 30 yıldır) \\
\hline Müslüm & 27 & Lise & 4.5 yıl \\
\hline
\end{tabular}




\begin{tabular}{|l|l|l|l|}
\hline Nevzat & 37 & Lise & Part time çalışan \\
& & & asıl işi memurluk \\
\hline Veysi & 21 & Lise terk & 3 sene \\
\hline Necmi & 30 & Ortaokul & 12 y1l \\
\hline Mehmet & 26 & Ön lisans (Maliye) & 1 ay \\
\hline
\end{tabular}

Günümüzde yemek hazırlama, sunumu ve tüketimi profesyonel bir faaliyet haline gelmiştir. Buna rağmen geleneksel kültürde yemek kültürünün tüm aşamaları tecrübelerle edinilmektedir. Bahattin Büryan Sarayı'nda çalışanlar, büryan hazırlama konusunda profesyonel bir eğitimden geçmemişler; bunun yerine usta çırak ilişkisi içerisinde mesleği öğrenmişlerdir. Buradan yola çıkıldığında, restoran çalışanlarının geleneksel kültürün takipçisi oldukları söylenebilir.

Pandemi koşulları gereğince maske, mesafe ve hijyen kurallarını dikkate alan çalışmada, katılımcılarla restoranda birebir görüşmeler gerçekleştirilmiştir. Çalışmanın gerçekleştirilmesine Siirt Üniversitesi Rektörlüğü Etik Kurulu 23.11.2020 tarihinde saat 10:00'da 91 numaralı oturum sayısında; sağlık alanında ise Siirt Üniversitesi Rektörlüğü Girişimsel Olmayan Klinik Araştırmalar Etik Kurulu'nca 31.12.2020 tarihinde saat 13:00'te 13 numaralı oturum sayısında izin verilmiştir.

\section{Yemek kültürü içerisinde et tüketimi ve Siirt kentinde Büryan}

İnsanların etle beslenme tavırları, belirli bir açıdan insan ilişkilerinin ve ruhsal yapılarının sahip olduğu dinamik hakkında bilgi vermektedir. Buna dayanarak Ortaçağ toplum yapısından yola çıkan Norbert Elias, belirli bir davranış biçiminin bir toplumsal merkezden çıkarak bütün toplumu etkisi altına aldığından bahsetmektedir. Ortaçağ' da bir toplumsal tabakada genellikle bütün Batı ülkelerinde belirli bir davranış biçimi egemenken, bir başka tabakada davranış biçimi tamamen farklıdır. Bu dönemde et yemek konusundaki tavırlar farklı kesimlere göre değişiklik göstermektedir. Dünyevi tabakada et tüketimi oldukça fazlayken, manastırlarda dini gerekçelerle (yemenin küçümsenmesi ve sınırlanması nedeniyle) etten imtina edilir. Alt tabakada, yani köylüler arasında et tüketimi oldukça sınırlıdır. Bunun nedeni, hayvanın o dönemde çok değerli olmasından, başka bir deyişle et bulamamalarından kaynaklanmaktadır (Elias, 2009: 214-5).

Elias'ın yapmış olduğu açıklamaya benzer şekilde, bölgelere göre verdikleri istatistiki bilgilerden yola çıkarak yaptıkları çıkarsamada Alan Beardsworth ve Teresa Keil (2011:332) küresel manada et yemenin varlıklı olmakla ilişkili olduğunu ifade etmektedir. Bu açıklama, yukarıda Elias'ın iddia ettiğine benzer şekilde etin statü belirleyici, tanımlayıcı özelliğine işaret etmektedir. Et, güçlünün yiyeceği olarak değerlendirilmekte iken; et yiyememe yoksulluğun, bazen isteyerek bazen de tesadüfen güçlüler topluluğun dişında kalmakla ilişkilendirilmektedir (Montanari, 2018: 29-30). Montanari'nin bu çözümlemesi, Avrupa'nın 
et yeme biçimindeki değişimle yakından alakalıdır. Avrupa'dakine benzer şekilde ülkemizde et, beslenmede önemli bir kaynak olarak değerlendirilmektedir. Zengin kesimler daha çok et tüketirken, nispeten daha düşük ve alt gelir gruplarından insanlar daha az et tüketmektedir.

Et tüketimi, farklı grup ve toplumlar düzeyinde kültür, cinsiyet, din, inanç biçiminden kaynaklanan belirleyicilere göre değişmektedir. Et yemenin yaşayış biçimi ve kültürle ilişkisini ifade eden bir örnek, göçebe hayat yaşayan Eski Türklerden hareketle verilebilir. Türklerin göçebe hayat yaşamaları nedeniyle zengin bir mutfak kültürü oluşturmaları mümkün değildi. En kolay pişen yemek, çıplak ateşte pişen ettir. Bu bağlamda Türklerde en eski ve en yaygın yemek ızgaradır. Orta Asya'da yaşamış Türkler bol bol at eti yemişti ve at sütünden mayalanmış kımız denilen içkiyi içmişlerdi (Belge, 2018: 121; Ögel, 1978). Görüldüğü gibi yaşam şartları yemek ve içecek kültürünün oluşmasını büyük ölçüde belirlemektedir.

Fransız Sosyolog Pierre Bourdieu, yiyeceğin sertlik derecesi arttıkça daha çok erkeklere özgü, salata gibi yeşillikler ile balığın ise kadınlara yönelik olduğunu ifade etmiştir. Bu noktada kadınlar etten az miktarda tüketirken, erkekler birkaç porsiyon alabilmektedir (Bourdieu, 2015: 282-3). Benzer şekilde birçok kültürde bazı besinler eril ve dişil anlamlar taşıyabilir. Besinlerin cinsiyete göre farklı anlamlar taşıması sıklıkla güç merkezi arayışından kaynaklanır. Güçlü besinler erilliği ve erillerin ihtiyacını temsil ederken, zayıf besinler dişiliği ve kadınların ihtiyacını temsil eder. Yine yoksulların tercih ettiği besin çeşitleri onların mücadele ettikleri ekonomik zorunlulukları yansıtırken, çocukların beslenme biçimleri (yetişkinlere) bağımlı olma durumlarını yansıtmaktadır (Beardsworth ve Keil, 2011: 92-3).

Yukarıdaki çözümlemelere benzer şekilde, katılımcılarımız eti ve özellikle de büryanı erkeklerin daha çok tükettiği konusunda hemfikirdir. Yine varlıklı olmanın bir göstergesi olarak ete verilen önem artmaktadır. Bununla beraber Siirt'te her kesimden insan eti tüketmektedir. Siirt kentinde et önemli bir besin kaynağıdır. Özellikle zengin tarif çeşitleriyle etin toplum yapısında etkileri bulunmaktadır. Siirt kenti özelinde düşündüğümüzde bunu bir katılımcımız şu şekilde ifade ediyor:

Siirt halkı ete baya bi düşü̈nür. Yani... Düşünün yani kahvaltıda bile et yiyen bir toplumuz yani şu an (İbrahim, 31 yaşında).

Yedi işletmede, dört büryan salonu işletmecisi ve ustası ile Siirt kentinin gastronomi açısından sürdürülebilirliğine ilişkin yapılan analizde hayvancılığa, ustalığa ve pişirilen tandırın önemine dikkat çekilmiştir. Bu üç maddeden biri olan hayvancılığın, besicilik yerine yaylak şeklinde yetiştirilmesinin büryan kalitesini etkilediği ifade edilmiştir (Coşkun vd., 2017: 395). Dolayısıyla büryanın kalitesini belirleyen unsurlar çok çeşitli olup bunlardan en önemlisini etin kalitesi oluşturmaktadır. Bu konuda katılımcımızın büryan için anlattıkları bir hayli önemlidir:

"Şimdi mevsimde iki et var. Bi toklu eti, bi kuzu eti. Toklu eti koçun bir ufağı oluyo. O da bu mevsimde yapılmaya başlanıyor. Yani ekim, kasım, kasımdan sonra yani. Kasım ayından aralık, ocak, şubat, mart, nisana kadar. Nisanda da kuzu etine başlıyoruz. Yani iki etten oluşuyor. Kuzu eti sütten kesilmiş kuzular, 7-8 aylık... Bunlar et toplamış olacak, erkek kuzular olmuş olacak... Toklu eti de besili olmayacak şekilde olacak. 
Yani bu toklu etler bir-iki saat dolaştırılıp daha sonra ahırlara koyulmuş olacak. Biz o etleri kullanıyoruz yani” (Mustafa, 44 yaşında, işletme ortağı).

Elias'a göre Ortaçağ' dan Yeniçağ'a geçerken etin servis biçimi de değişime uğramıştır. 17. yüzyıla dek Batılı üst sınıfta etin bütün olarak sofraya getirilişine ve sofrada parçalanmasına yönelik alışkanlıklar edinilmesinden, 20. yüzyılda et yemenin öldürülmüş hayvanla ilişkisini anımsamanın bir rahatsızlık nedeni olarak görülmeye başlandığı bir döneme geçilmiştir. Günümüzde ise etin formu yemek hazırlama esnasında o kadar gizlenmiş ve değişmiştir ki, etin kaynağı yemek sırasında asla akla gelmez. Öyle ki etin parçalanması tamamen ortadan kalkmamakla birlikte, sıkıntı ve huzursuzluk verici olay, toplumsal yaşantıda sahne arkasına aktarılır. Bu görevi uzmanlar dükkânda ya da mutfakta yerine getirirler (Elias, 2009: 21620). Avrupa'daki et hazırlama ve yeme kültüründeki dönüşüme benzer şekilde, Siirt'te de büryanın pişirilişi/yapılışı müşterilerin görebildiği bir yerde değildir (Fotoğraf 1-2-3). Buna rağmen Bahattin Büryan Sarayı'nda et bütün halinde restoranın giriş kısmında (dışarıdan görülebilecek şekilde) sergilenmektedir (Fotoğraf 4). Bununla birlikte etin parçalanışı yiyenlerin görebileceği şekilde yine aynı yerdedir. Dolayısıyla büryanın sergilenişi, hazırlanışı ve servisi müşterilerin gözü önünde gerçekleşmektedir (Fotoğraf 5-6-7).

Fotoğraf 1-2-3-4-5-6-7: Büryanın Hazırlanması ve Servisi
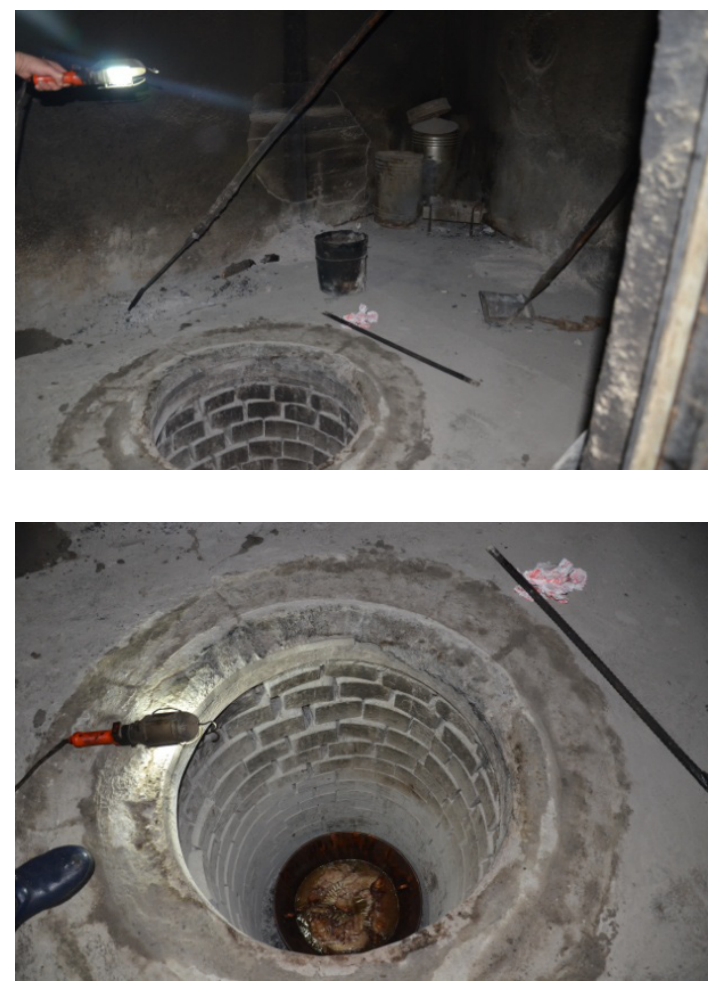

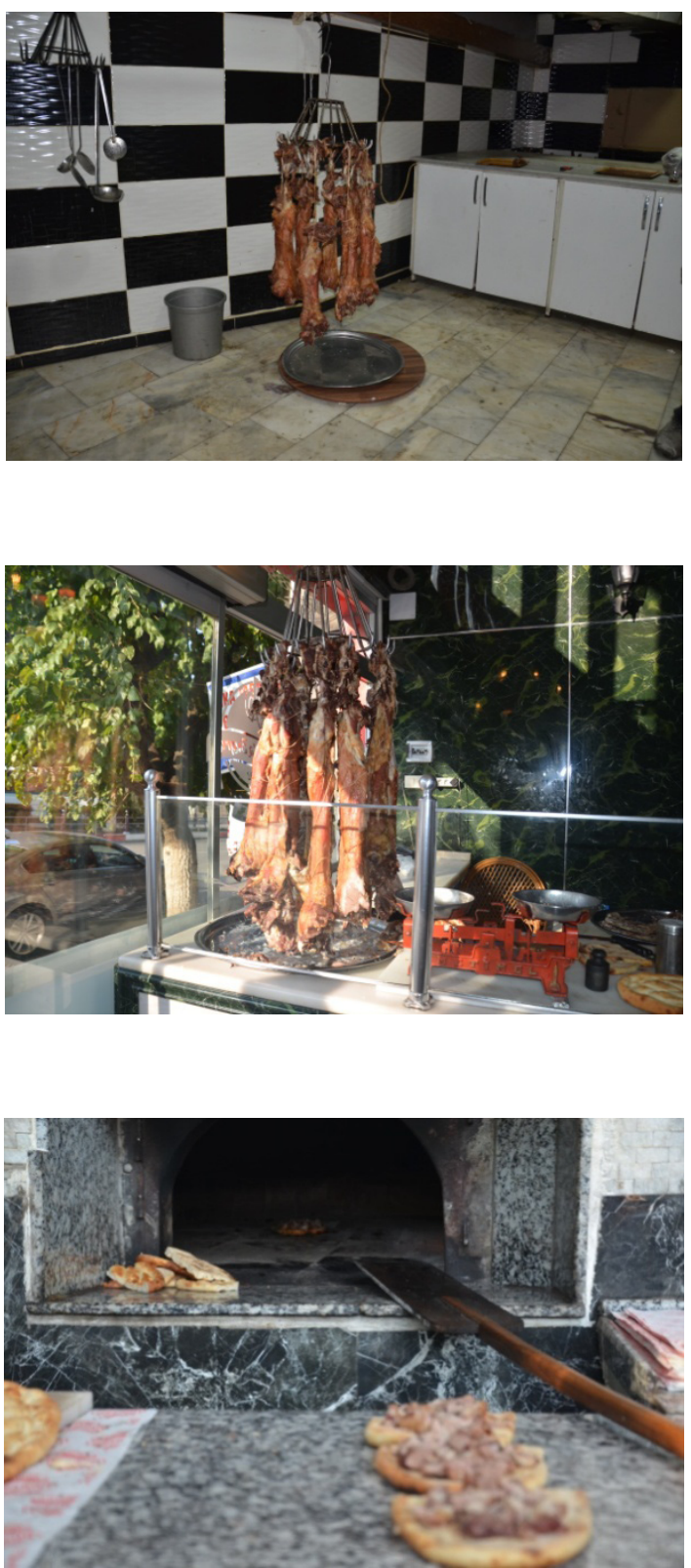

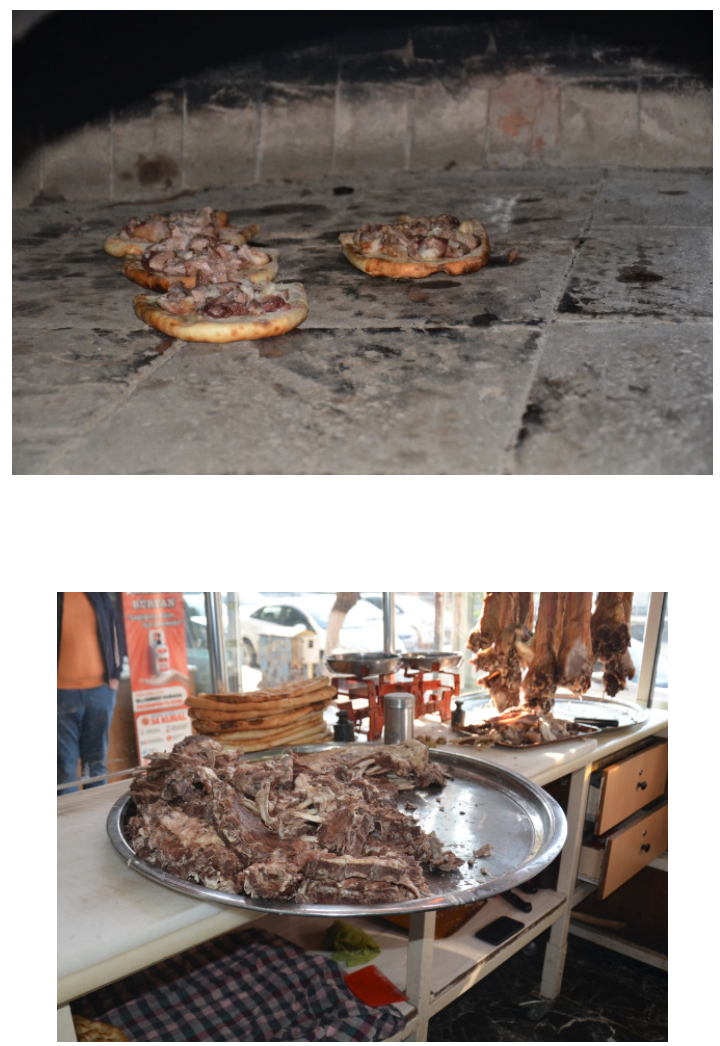

Büryan bir kültürel yaşantı sunması anlamında, göçebe kültürün temelinde yer alan hayvancılığı ve bununla ilişkilendirilebilecek yaşamı akla getirmektedir. Bununla birlikte misafirperver kültürü, alışkanlıkları, yöresel kimliği hazırlanışından servis edilişine kadar hissettirmektedir. Bu durum kent ve imgeleri üzerinden değerlendirildiğinde "slow food", “slow city” hareketiyle benzerliği açıktır. Jackson'a göre 1986 yılında İtalya'da McDonalds restoranının açılışını protesto eden bir grup aktivist ile başlayan slow food hareketi; yiyecek üreticileriyle tüketicilerinin, yiyeceğin kendisiyle tüketicilerinin ve sofrada bulunan kişilerin birbirleriyle etkileşimini kapsamaktadır (Akt. Güven, 2011: 114). Bu hareket geleneksel yemek kültürünü korumayı amaç edinmektedir. Kent ve imgeleriyle bir arada düşünüldüğünde bu durum uzun hazırlanma aşamalarından servisine ve sofradaki kişilerin birbirleriyle etkileşimine kadar pek çok aşamada yemeğin kent kültürüyle ilişkisini açığa çıkarmaktadır. Slow city ise yine İtalya'da başlayan bir hareket olup yiyecekleri, mekânları içine alacak şekilde yerel kültürel özelliklerin korunmasını amaçlamaktadır (Güven, 2011). Bu bağlamda Siirt'te büryan kebabı hazırlanmasından tüketimine kadar yavaşlık hareketiyle benzerlik taşımakta; yöre halkı, yerli ve yabancı turistlere farklı beğeniler sağlaması anlamında yerel kültürün sürekliliğini sağlamaktadır. 
Yukarıdaki fotoğraflarda da görülebileceği gibi etin servis edilişi pide iledir (Fotoğraf 5-6). Bu anlamda ekmeğin etle birleştirilmesi, temel besin olarak kültürel değerini göstermektedir. Öyle ki ikisi de kırsal özellikler taşıyan kent kültüründe vazgeçilmez besin maddeleridir.

\section{Siirt'te restoran kültürü ve Bahattin Büryan² Sarayı}

İnsan için yeme etkinliği gerekli besinin alınmasının ötesinde bir olgudur. İnsan yemek yerken sadece besin maddeleri değil, tat almaya yönelik birtakım deneyimler yaşamaktadır; birtakım anlam ve semboller tüketmektedir (Beardsworth ve Keil, 2011: 89-90, Çayc1, 2019: 99). Belirli bir gıda maddesi hakkındaki fikirler vücudun beslenme ihtiyaçlarını karşılama kabiliyeti kadar, o maddenin kişilere ifade ettiği anlam tarafından da şekillenmektedir (Çaycı, 2019: 99). Bu bakımdan Siirt'te de yemek sadece besin maddesi olarak değerlendirilmemelidir. Bunun ötesinde yemek, geçmişin muhafaza edildiği bir kültürel sürekliliktir.

Visser'e besinleri temin etme, hazırlama gibi faaliyetlerin yanında belki de en kolay faaliyetin yemek olması gerekmektedir. Ancak insanlar bu işlemi yemek yemek için belirli yer ve zaman, özel ekipmanlar, dekorasyon, belli bir sıra, birtakım davranışların sınıflandırılması ve bedenen uygunluk gibi bir kurallar sistemi içerisine yerleştirmişlerdir. Ona göre bunlar fiziksel bir ihtiyaç değil, tamamen bir kültür olgusudur (Akt. Beardsworth ve Keil, 2011:172). Doğaldan kültüre elde edilen veya üretilen yemek malzemeleri, düzen ve sıranın yemeyi oluşturması için mutfak kurallarından geçer ve yeme faaliyetleri sosyal zamanı kesmek veya noktalamak için programlanır. Sıradan yemek meşgaleleri üretimde (hafta sonları, hasat zamanları, başarılı avlanmalar), hayatın devrinde (doğumlar, evlilikler, ölümler) ve cemaatin hizmetinde (siyasi ve dini törenler) başlıca olanakları belirtmek için kullanılır (Goode, 2005: 172). Bu bağlamda yemek yeme etkinliği özel bir kültür gerektirmekte; ne yendiği ve nasıl yendiği kişileri büyük ölçüde belirlemektedir. Sözgelimi Batılı dünyevi üst tabakaların davranışlarındaki değişmeleri ele alan Norbert Elias, yemeğin nasıl yenileceğine dair ritüellerden biri olan sofra adabının yüzyıllar süren sosyal ilişkiler ve kullanım süreci içerisinde zamanla bugünkü işlevlerini ve biçimlerini kazandığını ifade etmiştir (2009: 203). Bahattin Büryan Sarayı'nda büryanın hazırlanması, sunumu ve tüketimi de, yukarıda vermiş olduğumuz alıntılarda benzer şekilde, yaşam koşulları ve kültürle alakalı şekil bulmuştur.

Tüketim konusunda gözlemlenen farkların esas ilkesi lüks/özgür beğeni ile zaruri beğeni arasındaki karşıtlıktır. Lüks beğeni özgürlükler veya bir sermayeye sahip olmanın sağladığı kolaylıklar tarafından belirlenmişken; zaruri beğeni ise bunun tam karşısında yer alır. Yemeiçme sanatı, halk sınıflarının meşru yaşama karşı çıkabildikleri alanlardan biridir (Bourdieu, 2015: 265, 268)3. Bu bağlamda yöresel yemek kültürü, mevcut koşullarda dayatılan beğeni ölçeklerine bir ölçüde karşı duruş ifade etmektedir. Geleneksel kent yapılarında et yeme sürdürülebilir bir alışkanlıktır. Siirt kentinde büryan yeme alışkanlığı, her kesimden insanın kendi sınıfsal varlığını koruduğu veya kendi sınıfsal varlığından kaçındığı bir yaşamsal edimdir. Bunda incelediğimiz büryan restoranının dört katlı ve her bir katın farklı müşterilere hitap eden özelliklere sahip olmasının payı bulunmaktadır. Nitekim aile salonu, teras, giriş 
kat gibi kısımlardan oluşan dört katlı büryan restoranında, kişiler kendi zevk ve beğenilerine uyan kısımda büryan yiyebilmektedirler (Fotoğraf 8-9-10).
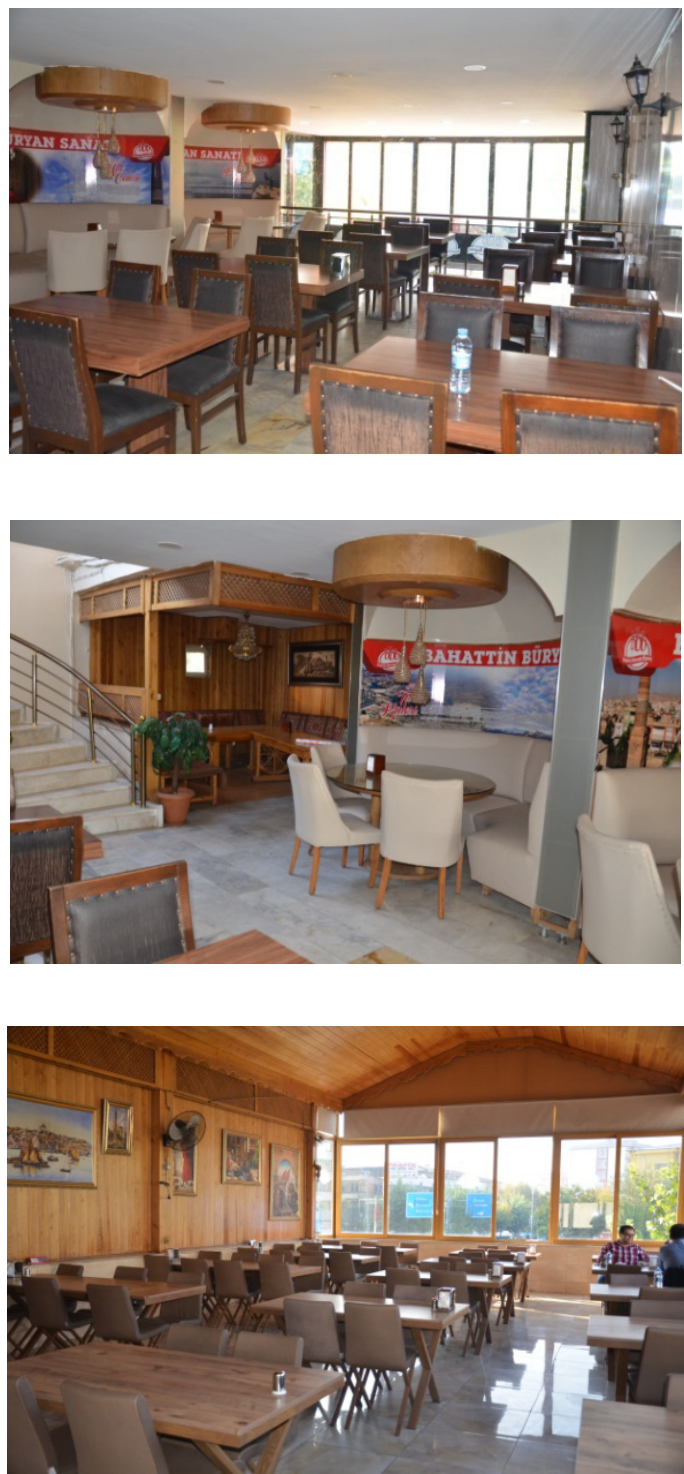

Bugünkü anlamıyla restorancılık 18. yüzyılda Fransa'da ortaya çıkmıştır. Özellikle Fransa ve Amerika'da restoranların yaygınlaşmasıyla, diğer ülkeler de bu gelişmeleri takip etmiştir. Ülkemiz açısından bu durum, farklı ülkedeki benzerleri kadar, yerel yiyeceklerin sunulduğu mekânların oluşmasına da zemin hazırlamıştır (Korkmaz, 2010: 128-9). Dışarıda yemek yemenin zorunlu bir faaliyet haline gelmesinin nedenlerinden biri, kent yaşamıdır. 
Buna paralel şekilde, kentte gerçekleşen çalışma hayatıdır. İş yaşamı, dışarıda sahiplenilmesi gereken yaşamsal alışkanlıklar doğurmuştur. Bundan dolayı restoran bir kültür değişmesini anlatmaktadır. Ancak bu alışkanlık edinimi mali, sosyal, kültürel farklılıklar içermekte; kişiler genellikle benzer beğenilere sahip oldukları kişilerle aynı mekânı paylaşmaktadır. Kimi zaman bu geleneksel kent yapılarında yöresel yemeğin üretildiği ve paylaşıldığı alışkanlıkların kavşağında bulunmaktadır. Bunlardan ülkemizde en çok bilinenleri arasında Güneydoğu Anadolu mutfağı yer almaktadır. Burada yemek bir zorunluluk olarak paylaşılmamaktadır. Bunun yerine yemek, ortak beğeniye sahip insanların paylaştıkları bir kültürel faaliyet görünümündedir.

Dışarıda yemek yemenin ticarileştirilmesi geleneksel toplumsal ilişkilerdeki bozulmanın sonucudur (Beardsworth ve Keil, 2011: 206-7). Bu durum modern kentler için doğru olmakla birlikte, geleneksel kent yaşamı için tartışmalıdır. Bilindiği gibi modern kent yaşamında ilişkiler, sınırlı bir zorunlulukla sürdürülmektedir. Elbette restoran kültürü bundan pay almaktadır. Ancak çalışmamız kapsamında ele aldığımız restoran, geleneksel toplumsal ilişkiler lehine pozisyon edinmektedir. Öyle ki Siirt halkı paylaşım ağlarını ev dışına çıkarmakla mali, hazırlık, temizlik, misafir ağırlama gibi farklı düzeydeki sorumlulukları azaltmaktadır. Böylelikle dışarısı, her kesimden insan için, yemek yemenin kolay bir yolu gibi görünmektedir. Bahattin Büryan Sarayı hazırlaması zahmetli bir yerel lezzeti üyelerine sunan kültür taşıyıcısı rolü üstlenmektedir. Çoğunlukla tanıdık ilişkiler ağıyla sahiplenilen bu restoranlar, evin mahrem alanının sunduğu konforu ve rahatlığı takipçilerine sunmaktadır. Bu bağlamda, ev dışında misafir ağırlama ve sosyalleşmenin statü sağlayıcı yanı ile birlikte içinde bulunan kültürün sürekliliğini sağlamaktadır. Her kesimden insana hitap eden bu yerler, kişilere lezzet ve alışılmış olanın dışında deneyim sağlamaktadır. Bahattin Büryan Sarayı özelinde bu durum yiyeceğin ve (domates, soğan, biberden oluşan) salatanın servis ediliş biçimi, etin pide arasında sunumu gibi detaylarla yerel kültürün restoran yapılanmasının dışında olmadığını göstermektedir.

İncelediğimiz restoranın birçok özelliği modern standartlaşmaların karşısındadır. Modern standartlardan farklı olarak restoran çalışanları arasında iş kolları ciddi bir şekilde ayrılmamaktadır. Çalışanlar garson, usta, hizmetli, işletme sahibi olarak kendilerini tanımlamaktan kaçınmışlardır. Çalışma esnasında her çalışan diğer çalışanın işlerini üstlendiğini ifade etmiştir. Mekânın içerisindeki bu yardımlaşma ağı, herkesin kendini tanımladığı-tamamladığı bir mekân kültürünün oluşturulmasına aracılık etmiştir. Başka bir anlatımla restoranda işin gerçekleştirilmesinde olduğu gibi, mekân da tüm çalışanlarca sahiplenilmiştir. $\mathrm{Bu}$ bağlamda çalışmada bizde katılımcıları tamamlarken, işletme sahibi dışında usta, garson, hizmetli gibi adlandırmalar yapmadık. Bunun yerine katılımcılarımızın tamamını çalışan olarak değerlendirdik.

Bir başka husus çalışanlar arasındaki ilişkidir. Bilindiği üzere modern işletmelerde müşterilere çalışanlar ve restoran sahibi tanıtılırken bey, hanım gibi tanımlayıcılar ismin yanında kullanılmaktadır. Oysa Bahattin Büryan Sarayı'nda çalışanlar gerek görüşme kayıtlarında gerekse kayıtlar dışında böylesi tanımlayıcıları tercih etmemiştir. Bunun yerine çalışanlar birbirlerinden "ağabey-kardeş" olarak bahsetmektedir. 
Bahattin Büryan Sarayı'nda büryan yavaş hazırlanmaktadır; müşteriler ve çalışanlar arasındaki ilişkiler ise dostça ve yakındır. Bu bağlamda restoran, modern standartlaştırmaların karşısındadır. Restorana gelen müşteriler çalışanlarca tanınmaktadır. Aynı şekilde müşteriler de mekânın ve büryanın sunuluş biçimi kadar, çalışanların candan ve sıcak tavırlarından hoşnut görünmektedir.

Diğer yandan incelediğimiz restoranda insanlar kültürlerine ve damak zevklerine ait bir alışkanlığı, gündelik hayattaki modern saat kısıtlamalarının dışında gerçekleştirmektedir. Çalışanlar bu sınırlamayı bir başka yerel sınırlılıkla telafi etme eğilimine girmektedir. Buna göre büryan ancak sabah saatlerinde tüketilebilen bir yiyecektir. Restoranın müşterileri bu kurala riayet etmektedir. Çünkü katılımcılarımızdan birinin ifade ettiği gibi, saat ilerledikçe etin kalitesi düşmektedir. Bu yiyeceğin hazırlanması ve servis aşamalarında yaygın görülen bir özelliktir.

Gece 2'de ... Ustamı geliyor. 5 'te servise hazır oluyor. Genelde akşam 5 gibi de bitiriyoruz. Daha erken bittiği de oluyor tabi (İbrahim, 31 yaşında).

Üstelik bu yaşamsal alışkanlık sadece beslenme ile değer bulmamıştır. Özellikle büryanın tarihi geçmişini bir katılımcımız göçebe kültür, hayvancılık, din gibi unsurlarla ilişkilendirerek açıklamaktadır. Büryanın Siirt’te ortaya çıkmasının nedenini sorgulamaya açtığımızda katılımcımız bunu kervanların geçiş güzergâhında olmasına bağlamaktadır:

“....kervancılar vard1. Siirt'e gelip konakladıkları zaman o gece misalen sabah namazını kılarlardı ve büryan kebabına damlarlardı. Büryan kebabı da bunları tok tutuyo. Yani herkesi tok tutuyo... Bunlar da uzun yola çıkacakları için hep eti tercih ederlerdi... Özellikle yani sabah, sabah namazlarını kılıp büryanlarını yer öyle yola koyuluverirlerdi. Yani kervancılara bağlı bir kültürdür bu, ordan gelmedir yani...." (Mustafa, 44 yaşında, işletme ortağı).

Tarihe dayandırılan bu açıklama, kültürel süreklilik içerisinde büryanın bölgede önemli bir değeri olduğunu göstermektedir. Bununla birlikte bir kentin olanakları, büyüklüğü kişiler için yaşamsal avantajlar sağlamaktadır. Gelişmişliğin bir ölçüsü olarak dışarıya açık olmayı, dışarıyla etkileşim halini ele aldığımızda, Siirt'in bu konuda dezavantajı olduğu söylenebilir. $\mathrm{Bu}$ durum, aşağıdaki katılımcımıza göre Siirt'in köy olarak değerlendirilmesine kadar varabilmektedir. Bu görüş, diğer katılımcılarımızca da onaylamaktadır. Katılımcılarımız söz konusu olumsuz bakıştan kurtulmanın bir yolu olarak büryanı görmektedirler. Çalışanlar büryanla Siirt'in kültürel bir değer kazandığını, diğer kentler ve ülkelerce de tanındığını belirtmektedir. O halde bir şehrin markalaşmasının önemli unsurlarından biri yöresel kültürel özelliklerdir denilebilir. Öyle ki bu kültürel özellikler, büryanda olduğu gibi, yeterince tanıtıldığında şehir olarak anılmak kolaylaşmaktadır:

"Normalde Siirt küçük yer olduğu için herkes köy diyor buraya. Ama büryan denildi mi Siirt deniyor. (Veysi, 21 yaşında)

Ya şimdi biz büryan sayesinde Siirt ilinin ismi çıkıyor. Mesela ... Siirt dediğin zaman tanımaz. Ama ... Mesela dışarıdan gelenler abla buraya geldiği zaman Siirt büryanı diye hitap ediyor. Siirt olarak değil... İlk önce yemeğe geliyorlar, ondan sonra gezmeye gidiyorlar. (Mehmet, 26 yaşında) 
"Siirt'in nasıl desem özel yemeklerinden, başka hiçbir yerde yapılmaması, Siirt'le anılması, başka şehirlerde büryan derseniz Siirt denilir. Onun için Siirt'e önemli bir yer katıyor" (Veysi, 21 yaşında).

“...Biz bu sektöre girdiğimiz zaman, özellikle işlerimizi büyüttüğümüz zaman baya bi yayınlandık TVlerde, gazetelerde.. Büryan sayesinde Siirt'in adı çıktı. Yani kültürel şeyimiz arttı. Misafirler daha çok gelmeye başladı. Bunun sayede Tillo tanıtıldı. Daha böyle gezilecek yerler tanıtıldı. Büryan sayesinde oldu bunlar hepsi. Büryan olmasaydı Siirt varla yok arasında gibi bir şeydi yani” (İbrahim, 31 yaşında).

\section{Fotoğraf 11-12: Basında Bahattin Büryan Sarayı}
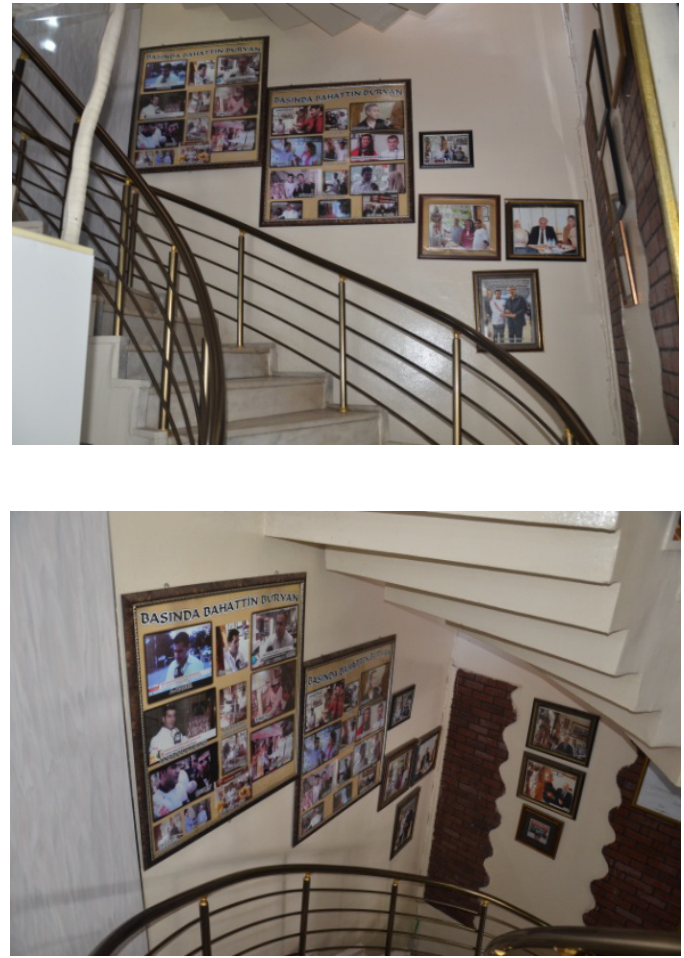

"Siirt mesela bundan 15-20 y1l önce kimse Siirt'i bilmezdi. Yani ... Abi, ... Usta (restoranın işletmeci ortağ1 kastediliyor) sayesinde gelişti yani bunu diyebiliriz. Yani her gün televizyonlarda. Bundan önce kimse Siirt'e gelmez, büryan yemezdi şehir dışından. Şimdi her gün her gün şehir dışından buraya gelenler var. Türkiye'nin neresine gidersen Siirt'i sorduğun zaman büryanı söylerler” (Necmi, 30 yaşında).

“ Şu an müşterilerimizin \% 50'si yerel \% 50'si yabanc1 efendim. Zaten Siirt'teki memur olsun, öğretmen olsun, polis olsun, diğer farklı kurumlarda olsun çalışan yabancı misafirlerimiz olsun gerçekten yani her haftada, yani her gün de olmasa haftada 1-2 
günü gerçekten büryanla yemekle geçiriyorlar yani kendileri... Özellikle hafta sonu...

yabancı misafirlerimiz buraya geliyorlar" (Nevzat, 37 yaşında).

Yemek kültürü, zaman içerisinde, tam bir kentli görünüme bürünmüştür. Sözgelimi Avrupa'daki yemek kültürünün değişimini temele alan bir çalışmada, yalnızca endüstriyel sistemin değil, kentli beslenme modellerinin artık kural koyar hale gelmesinden ve herkes tarafindan taklit edilebilmesinden bahsedilmektedir (Montanari, 2018: 189). Bu konuda kuşkusuz, kamusal yaşamın dinamikliği ve kadının iş hayatına katılmasının belirgin etkisi bulunmaktadır. Kırsalda her alanda sürdürülen birliktelikler, kent yaşamına geçişle sınırlı ilişkilerin sürdürüldüğü mekânlara doğru evrilmiştir. Bunun bir sonucu olarak yemek, buluşmanın yeni aracısı konumunda olup, lokantalar ve restoranlarla birlikte gelişim göstermiştir. Kırsal özellikler taşıyan kentlerde ise geleneksel kültür büyük ölçüde devam etmektedir. Bunlardan biri özel ve kamusal alan arasındaki farklılıktır. Yukarıdaki katılımcılarımızın açıklamalarına bakıldığında, modern kültürün keskin ayrımlarından biri olan restoran çalışanları ve müşteriler arasındaki farklılaşma, Bahattin Büryan Sarayı'nda yaygın bir alışkanlık olarak karşımıza çıkmamaktadır. Bunun yerine müşterilere yönelik “misafir” sözcüğü katılımcılar arasında yaygın bir şekilde kullanılmaktadır. Bu durum bize büryan restoranının özel ile kamusal alan arasında konumlandığını göstermektedir.

Büryanın kültüre yansıyan farklı örneklerinden günlük konuşma ve şiir nasibini almıştır. Bir katılımcımız bunun sadece bir kebap değil, kültürün her alanına hitap eden bir alışkanlık olduğunu şu sözlerle açıklamaktadır:

"Etin kızartılmış anlamını taşıyor bu büryan. Şimdi büryan kelimesi Farsça'dan türemiş bir kelime Osmanlıca'dan... Eskiden küçük bir çocuk bir kabahat işlediği zaman, yüzü kızardığı zaman işte derlerdi çocuğa: 'Yüzün büryan gibi olmuş. Hayırdır ne kabahat işlemişsin?' Bazı şiirlerde geçiyor işte ‘ciğerim yandı büryan oldu'. Yani ciğeri o kadar kızarmış ki var ya o kadar yanmış ki büryan olmuş..." (Mustafa, 44 yaşında, işletme ortağı).

Büyük şehirlerde yöresel mutfaklar, en pahalı menüleri sunmaktadır ve otantik ortamlarıyla belirli bir zümreye hitap etmektedir. Bu restoranlar seçkin müşterilerini küresel tek tip yeme standardından kurtarıp onlar için ayrıcalık üretmektedirler (Beşirli, 2017: 150). Oysa herkesin ulaşabildiği ve aynı şekilde tükettiği besin sıradanlaşan ve tüketicisine imtiyaz sağlamayan besindir. Kişilerin yaygın olarak tüketmediği nadir besinler ise tüketicisini imtiyazlı bir hale getirmektedir (Beşirli, 2017: 156). Yöresel yiyeceklerle her kesimden insan, geleneksel kültürün içinde olağan bir alışkanlık olarak yemeyi benimsemektedirler. Bu bağlamda Siirt büryanı olağan bir yemek kültürüdür denilebilir. Bu durum aynı bölgedeki kişiler için ayrıcalık olarak ifade edilemese bile, içinde bulunulan kent kültürü için bir avantajdır. Nitekim geleneksel kent kültürünü diğer kentlerden daha cazip hale getirmektedir. Böylelikle yemeye dayalı olanaklar, farklı çevrelerden kişilerin yoğun bir şekilde tercih ettiği alışkanlık haline gelebilmektedir.

"Sanki müptela oluyor insan, alışıyor. Alışıyor insan... Hani uyuşturucu bağımlılığı, sigara bağımlılık yapıyor ya... Bu da bağımlılık yapıyor yani sanki insanda. İnsanın her gün yemesi geliyor. Ama maddi durum izin verirse" (Veysi, 21 yaşında). 
"Biraz daha yani biraz daha aileye yönelik şeylerimiz var. Terasımız var, aile katlarımız var. Yani hizmette diğerlerine göre bir üst seviyedeyiz. Daha iyi tabi yani şehrin göbeğinde. Herkesin buraya gelip yemek yiyebileceği bir yer... Herkes geliyor evet... Herkesin takip ettiği bir yer. Köylerimizden gelen misafirlerimiz oluyor...” (İbrahim, 31 yaşında).

Siirt'e gelen herkes ilk önce büryanı sorar. Önce büryan... Önce büryanı yer ondan sonra gider gezer" (Müslüm, 27 yaşında).

Yukarıdaki katılımıılarımızın açıklamalarına dikkat ettiğimizde, farklı kesimlere hitap eden bir kültürel alışkanlık olarak büryanın sahiplenmesinin nedeni anlaşılmaktadır. Diğer taraftan yerel yiyecekler bir yörenin sahip olduğu kültürün değerini yükselten öneme sahiptir. Yöresel yiyecekler yöreye özgü yiyecek ve içeceklerin ekilip biçilmesinin devam etmesine, yerel ekonominin canlanmasına, istihdam olanaklarının gelişmesine katkıda bulunmaktadır (Çapar ve Yenipınar, 2016: 110). Aynı zamanda yerel yiyecekler, belirgin bir alışkanlık ile faaliyetlerin birbirinden ayrılmamasını sağlamaktadır. Kültüre ait etkin bir faaliyet kolu olduğu düşünülebilirse düğün, cenaze, buluşma, ayrılma gibi pek çok yaşamsal edimde büryanın etkisinin olduğu fark edilebilecektir. Bunun içinde büryan sosyalleşmenin ve buluşmanın, misafir ağırlamanın, toplantı ve yerel kültürü paylaşmanın önemli bir aracısıdır.

Daha önce de değindiğimiz gibi, modern kültürde işin profesyonel bir meslek kolu haline gelmesiyle, müşteri ve çalışan arasındaki ayrım belirginleşmektedir. Beardsworth ve Keil'e (2011:206) göre, dışarıda yeme kişisel sosyal yükümlülükler ile ilişkiler tarafından şekillenmektedir; diğer taraftan hizmet veren ve müşteri arasında ticari bir bağ yaratmaktadır. Oysa incelediğimiz büryan restoranında bu tür bir standartlaşma kültürel dokunun etkisiyle dışarıda bırakılmıştır. Nitekim katılımcılarımız müşterilere misafir olarak hitap ederek böylesi bir standartlaşmayı baştan yok saydığını göstermektedirler.

Büryanın yiyecek olarak tercih edilmesinde kültürel dokunun yanı sıra pek çok etken belirleyicidir. Bunlardan kuşkusuz en ilgi çekici olanı küresel pandemi şartlarında sağlık alanında güvence sağlamasıdır. Her ne kadar araştırmamız sırasında böylesi bir çalışmaya rastlamamış olsak da Siirt halkını büryan tüketmeye sevk eden birtakım nedenler mevcuttur. İçerdiği proteinin sağlamış olduğu dayanıklılık hali kadar, bağışıklık sistemini güçlendirdiği konusunda verilen tavsiyeler, tok tutucu özelliği büryanın tercih edilmesinde belirleyici unsurlar olarak karşımıza çıkmaktadır:

\footnotetext{
"Büryan diğer yemeklere göre biraz daha hafif bir yemek. Bi de tok tutuyor. Sabah gelip kahvaltı yaptığınız zaman akşama kadar sizi tok tutabiliyor yani. Bi de zararsız... Doktorlar da tavsiye ediyor. Özellikle de bu pandemi döneminde... Doktorlar baya bi tavsiye ediyor... Bi iki hafta önce bir tane doktor geldi. Böyle yan yapan bir doktorumuz... Geldi burada etle ilgili bi konuşmalar yaptı. Yani halka tavsiye etti. Özellikle koronadan dolayı baya bi tavsiye etti. İyi geliyormuş yani. Tabi proteini yüksek... Yani iyi... Bağışıklığı güçlendiriyormuş" (İbrahim, 31 yaşında).
} 


\section{Sonuç}

Ülkemizde restoran ve lokanta birbirinin yerine kullanılan iki kavramdır. Her iki kavram da, modernleşmenin etkisiyle gündelik dile yerleşmiştir. Osmanlı Devleti'nde çağdaş anlamda lokanta II. Meşrutiyet sonrasında günlük yaşama girmiştir. 1890-1920 yılları arasında Avrupai tip yemeğin öncüleri otellerin restoranları olmuştur (Gürsoy, 2019: 149). Çalışmada Bahattin Büryan Sarayı için, Siirt kenti koşulları dikkate alınarak, restoran kavramı kullanılmıştır. Bunda restoran kavramının kökeninin et suyundan türemiş olması (Spang, 2007: 19-20), restoranın ilk ortaya çıktığında muhtemelen şifa arayan daha özel bir kitleye, lokantanın ise genel aileye ve mahalle şenliklerine yemek sağlamak vaadinde bulunması (2007: 51-2) ve Bahattin Büryan Sarayı'nın takipçilerine Siirt kenti koşulları içerisinde daha modern bir mekân ve kültür sunmasının katkısı büyüktür.

Siirt'te yemek beğenisine insanlar, kültürel yaşamın bir getirisi olarak adapte olmuşlardır. Siirt yemek kültürü içerisinde büyük bir ağırlığı olan büryan din, göçebelik, hayvancılık gibi unsurlar tarafından şekillenmiştir. Büryan hazırlanmasından tüketimine kadar yöresel etkileri sıcak, samimi, tanıdık ilişkilerle sürdürmektedir. Çalışmamızın evrenini oluşturan Bahattin Büryan Sarayı'nda yerel kültürün ağırlığıyla geçmiş alışkanlıklar büyük ölçüde devam etmektedir. Kuşkusuz bunda sınıflar arası beğeni farklarının artmasında etkili olan mekânların oluşmamasının payı bulunmaktadır. Bahattin Büryan Sarayı'nda farklı dile, etnik kökene ve sınıfa mensup insanlar kendi kültürel özellikleriyle bağlarını tazelemektedir. Restoranda ailece yenilen yemeklerin yanı sıra arkadaş buluşmaları, misafir ağırlama, iş toplantıları yapılmaktadır. Bu bakımdan restoran kamusal ve özel yaşamın dinamiklerini içerisinde taşımaktadır.

Yöresel yemekler toplumların ekonomik, tarihsel ve kültürel özelliklerinin etkisiyle oluşmaktadır. Tescilli bir ürün olan büryan Siirt halkının duyuş, düşünüş ve hissediş biçimlerini yansıtmaktadır. Bu bakımdan büryanın varlığı somut olmayan kültürel mirasının muhafazasında etkilidir. Siirt'te büryan kebabı ile kentin özellikleri olan yavaşlık, sadelik ve kültürel uyum açığa çıkmaktadır. Benimsenen bu alışkanlığın korunması için yöre halkının ve işletmecilerin yaptığı çalışmalar olup bu konuda yapılanların artırılması gerektiği açıktır. Nitekim günümüzde turizm tek bir kaynaktan beslenmemektedir. Siirt'in Türkiye'nin diğer illerine kıyasla cazip bir ulaşım ağına ve denize sahip olmaması, turistik mekânlarının azlığı, sıcak iklimi gibi nedenler yerli ve yabancı turistlerin kenti tercihleri için dezavantaj oluşturmaktadır. Bütün bu dezavantajlara rağmen çalışmamızın bize gösterdiği gibi Siirt kentinin tanıtılmasında büryan önem taşımaktadır. Sözgelimi dışarıdan gelen memurların ve turistlerin öncelikli olarak büryanı sorması yöresel yemek kültürünün önemine dikkat çekmemizi kolaylaştırmaktadır. 


\section{Notlar}

1 Araştırmada, gizlilik ilkesi uyarınca katılımcılara takma isimler verilmiştir.

2 Coğrafi İşaretlerin Korunması Hakkındaki Kanun Hükmünde Kararname'yle Siirt'in yöresel tescilli yemeği olan büryan 27.07.2003 tarih ve 25181 sayılı Resmi gazetede ilanı ile tescil edilmiştir (Türk Patent Enstitüsü 2003).

3 Son söylediğimiz fikrin karşısında savlar bulmak çok da zor görünmemektedir. Buna göre yiyecek toplumsal farklılaşmanın kaynaklarını ifade etmek için güçlü bir sembolik kaynaktır. Yiyeceklerin toplumsal ayrımları simgelemek ve göstermek için önemli rol oynadığı açıktır. Nitekim spesifik gıdalar, yüksek konumu veya sosyal açıdan üstün estetik zevkleri olan yüksek bir sosyal sınıf konumu ile ilişkilendirilmektedir. Bunun aksine diğer gıdalar düşük bir sosyal sınıfı, düşük statüyü ve (ekonomik ve estetik) yoksulluğu sembolize edebilmektedir (Çaycı, 2019: 100; Beşirli, 2017:

27-8). 4 Yazarın beyanı: Çalışmanın gerçekleştirilmesine Siirt Üniversitesi Rektörlüğ̈̈ Etik Kurulu 23.11.2020 tarihinde saat 10:00'da 91 numaralı oturum sayısında; sağlık alanında ise Siirt Üniversitesi Rektörlüğü Girişimsel Olmayan Klinik Araştırmalar Etik Kurulu’nca 31.12.2020 tarihinde saat 13:00'te 13 numaralı oturum sayısında izin verilmiștir.

\section{Kaynakça}

Beardsworth, A., Keil, T. (2011). Yemek ve toplum çalışmasına bir davet: Yemek sosyolojisi (A. Dede Çev.) Ankara: Phoenix.

Belge, M. (2018). Tarih boyunca yemek kültürü. (15. Bask1) İstanbul: İletişim.

Beşirli, H. (2017). Yemek sosyolojisi: Yiyeceklere ve mutfağa sosyolojik baklş. (2. Baskı) Ankara: Phoenix.

Bourdieu, P. (2015). Ayrım: Beğeni yargısının toplumsal eleştirisi (D. Fırat, G. Berkkurt, Çev.) Ankara: Heretik.

Ceylan, Y., ve Samırkaş Komşu, M. (2020). Coğrafi işaretli ürünlerin bölgesel turizmin gelişimi açısından değerlendirilmesi: Siirt ili örneği. Journal of Humanities and Tourism Research, (Özel Say1: 5), 59-75.

Coşkun, K., Künç, S., Çelik, S., Acar, S. (2017). Siirt ilinin gastronomik açıdan sürdürülebilirlik analizi: Büryan örneği. 1st International Sustainable Tourism Congress içinde (391397), November 23-25. Kastamonu.

Çapar, G., Yenipınar, U. (2016). Somut olmayan kültürel miras olarak yiyeceklerin turizm endüstrisinde kullanılması. Journal of Tourism And Gastronomy Studies, 110-115.

Çayc1, A. E. (2019). Küreselleşen yemek kültürünün dönüşümünde sosyal medyanın rolü: Instagram gurmeleri. İstanbul Ticaret Üniversitesi Sosyal Bilimler Enstitüsü Doktora Tezi.

Elias, N. (2009). Uygarlık süreci 1, (5. Bask1). (E. Ateşman, Çev.) İstanbul: İletişim. Goode, J. (2005). Yemek (F. Mormenekşe, Çev.) Millî Folklor. 17 (67), 172-176.

Gürsoy, D. (2019). Tarihin süzgecinde mutfak kültürümüz. (4. Baskı). İstanbul: Oğlak. 
Güven, E. (2011). Yavaş güzeldir: "yavaş yemek” ten "yavaş medya” ya hızlı tüketime dair bir çözüm önerisi. Selçuk Illetişim, 7(1), 113-121.

Işkın, M., Şengel Ü., Zengin, B. (2017). Destinasyonların tanınırlığında yerel yemeklerin rolü: Büryan Kebab1 örneği. IWACT International West Asia Congress of Tourism Research içinde (324-331). 28 Eylül-1 Ekim 2017. Van-Türkiye.

Kılınç, N. (2019). Siirt ve çevresinin turizm coğrafyası. İstanbul Üniversitesi Sosyal Bilimler Enstitüsü, Yayımlanmamış yüksek lisans tezi.

Korkmaz, E. Geçmişten günümüze restoranlar: Türkiye'de restorancılığın gelişimi. V. Lisansüstü Turizm Öğrencileri Araştırma Kongresi. 27-30 Mayıs 2010-Nevşehir, 120130.

Montanari, M. (2018). Kıtlık ve bolluk: Avrupa'da yemeğin tarihi. (M. Önen, B. H. Çoban, Çev) Ankara: Nika.

Neuman, W. L. (2016). Toplumsal araştırma yöntemleri 1-2. (8. Basım). (S. Özge, Çev.) Ankara: Yayın Odası.

Ögel, B. (1978). Türk kültür tarihine giriş $I V$ : Türklerde yemek kültürü. Ankara: Kültür Bakanlığ1.

Spang, R. L. (2007). Restoranın icadl: Paris ve modern gastronomi kültürü (B. S. Şener, Çev.) Ankara: Dost.

Türk Patent Enstitüsü (2003). Siirt büryan kebabı. No: 68-Mahreç İşareti.

Yıldız, Ö. (2020). Yiyecek, kültür ve turizm ilişkisi (A. Akbaba, N. Çetinkaya, Ed.) Gastronomi ve yiyecek tarihi içinde (73-92). Ankara: Detay.

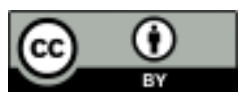

Bu eser Creative Commons Atıf 4.0 Uluslararası Lisansı ile lisanslanmıştır. (This work is licensed under a Creative Commons Attribution 4.0 International License). 